\title{
Leadership styles and relational energy: Do all leaderships styles generate and transmit equal relational energy?
}

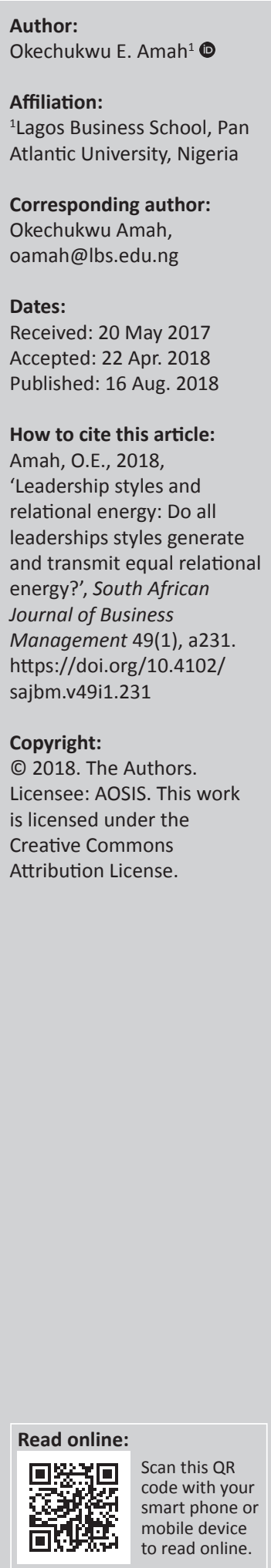

Background: Despite the espoused importance of relational energy, and the fact that it is generated in interaction between leaders and their subordinates, little is known about which leadership style generates the highest relational energy.

Objectives: The purpose of this study was to determine if there are differences in the levels of relational energy generated and transmitted when employees interact with leaders who exhibit autocratic, transactional, transformational and servant leadership styles.

Method: The study utilised scenario-based experimental methodology to gather data. Five leadership experts reviewed the description of each leadership style prior to use in the study. A pilot study was carried out with 40 executive education participants to establish that the description of each leadership style was different and identifiable by non-experts. Fifty-two executive Master of Business Administration (MBA) participants from various organisations in six industries in Lagos, Nigeria, provided data for the scenario analysis. To avoid errors, the data for each style were collected separately. Data analysis was performed using analysis of variance and Tukey's honest significant difference test.

Results: The results of the scenario analysis showed that indeed there is a difference in the relational energy generated when employees interact with different leadership styles.

Conclusion: The results have practical implications for the selection and training of individuals to be placed in leadership positions. Leadership selection and training must emphasise servant leadership. This is the first study to empirically establish that different leadership styles generate and transmit different levels of relational energy during interaction with employees.

\section{Introduction}

Positive energy is an important organisational resource that enhances individual and organisational performance. Within an organisational setting, positive energy from one individual can enhance other organisational participants' motivation to work because of its contagious nature (Quinn, Spreitzer \& Lam 2012; Schippers \& Hogenes 2011). Conversely, negative energy from an individual can spread to others and deplete their motivation to work. Therefore, it is necessary to monitor and control the level and nature of energy the individuals in an organisation possess. It becomes very necessary when such individuals are leaders who interact with and control other organisational participants. Various metaphors have been used to describe what energy does in an organisation. For example, organisational participants consider the level of energy around a team to denote the level of success a team can achieve (Cross, Baker \& Parker 2003). Energy is defined as how employees are 'mentally engaged, enthused, and willing to commit efforts to possibilities' (Cross et al. 2003:51) while carrying out assigned tasks. Relational energy is a major component of the organisational energy generated and transmitted when participants interact with each other in the course of their work assignments. This study will be limited to the relational energy generated and transmitted when leaders interact with their subordinates. Relational energy has been established to serve as a 'resource bank', which employees can acquire, store, maintain and utilise at various times in their work life (Amah 2016: 135). Owens et al. (2016: 37) define relational energy as the level of psychological resourcefulness generated from interpersonal interaction that enhances one's capacity to do work'. This form of energy affects individual productivity and organisational learning (Cross et al. 2003), reduces the effects of work-family conflict on highly engaged employees (Amah 2016) and affects employee engagement directly (Owens et al. 2016). Positively energised employees carry out assigned tasks quickly and enjoy every aspect of the tasks (Schippers \& Hogenes 2011). It is an organisationally valued 
resource that can be enhanced through positive interaction with leaders and reduced when interactions are negative.

Interactions between leaders and their subordinates can either be positive or negative and hence energising or deenergising (Bruch \& Ghoshal 2002). The nature of this interaction differentially affects employee performance (Amah 2016; Stone, Russel \& Patterson 2004). Because relational energy is also generated during interaction, it is likely that leadership styles with positive or negative interactions will generate different levels of relational energy. Certain studies have determined the differential effects of different leadership styles on other important individual work outcomes (Chatbury, Beaty \& Kriek 2011; Cho \& Jung 2014; Holten \& Brenner 2015; Lyons \& Schneider 2009; Moorosi \& Bantwini 2016; Saeed et al. 2014;). However, the author does not know of any study that has empirically tested if different leadership styles generate similar relational energy or not during interactions with subordinates. Certain past studies point to the possibility of this difference. For example, Bernhard and O'Driscoll (2011) find out that transformational and interactional leadership styles have differential effects on the creation of psychological ownership in family-owned businesses. Cross et al. (2003) allude to the possible difference during interaction; however, the authors make no reference to leadership style. The importance of relational energy in the functioning of employees and how it is generated through interaction with leaders has been established by past studies (Amah 2016). However, there is a need to fill the gap in the knowledge of how different leadership styles affect the relational energy level of employees. The filling of this gap was suggested by Dierendonck et al. (2014) and Avolio, Walumbwa and Weber (2009) in their past studies.

The aim of the current study is to determine if there are differences in the level of relational energy generated and transmitted when employees interact with leaders enacting different leadership styles. Understanding this is necessary because of the role leadership and relational energy play in the performance of employees, organisational productivity and employee engagement (Amah 2016). By establishing the differential effects of different leadership styles in generating and transmitting relational energy, this study provides empirical justification for organisations to select leaders with the right leadership mindset and train future leaders to use effective styles in dealing with subordinates.

\section{Theoretical background and hypotheses}

\section{The generating and transference of relational energy in social interaction}

Despite the espoused importance of relational energy, it has received little emphasis in organisational discussions (Schippers \& Hogenes 2011). However, its importance is hidden within certain terms that imply the presence of energy in one form or the other (Schaufeli et al. 2002;
Schippers \& Hogenes 2011). Relational energy is one of the organisational resources that can help highly engaged employees to function effectively and still avoid the negative effects of high work-family conflicts experienced while providing extra-role activities to the organisation (Amah 2016). A positive aspect of this energy is that it can be stored, utilised and further enhanced during future interactions. Hence, employees gravitate to interactions perceived to have the potential to generate and transmit energy while avoiding those that de-energise or drain their energy resources. Because relational energy can be defined as having quantity, direction and intensity, it will likely vary depending on the quality of the interaction generating the energy.

Two theories explain the generation and transmission of relational energy, namely interaction ritual and social contagion theories (Collins 1993; 2004; Hartfield, Cacioppo \& Rapson 1994). Interaction ritual theory postulates that although feelings are unquantifiable, people are aware of its nature and presence in any interaction, and the experience of this shared emotion is more 'intensely' perceived (Collins 2004:48). Interaction ritual focuses on the interaction between individuals, and its potential to elicit input and feedback of the emotional energy generated during the interaction. It recognises two types of interactions: that which produces emotional energy and that which depletes emotional energy. The nature of the interaction is determined by factors such as mood, mutual focus and nature of the group formed (Collins 1993; 2004). Employees gravitate to interactions that provide positive energy and avoid those that de-energise them because they see relational energy as a resource bank that can be increased and depleted when needed (Casciaro \& Lobo 2008).

Social contagion theory explains the propensity of behaviours, emotions, 'experiences, thoughts, and attitudes' from one person to be experienced and enacted by another person who is in social contact with the person producing them (Owens et al. 2016:37). The common awareness of the emotional and psychological happenings experienced and perceived by the interacting individuals becomes conduits through which the sharing takes place. The type of energy generated, positive or negative, is shared and transferred from one person to the other. Thus, the energy generated in the process of interaction becomes contagious and is shared by the party involved. Hence, organisational participants who are in constant need of acquiring and storing energy for future use (Hobfoll 1989; Hobfoll \& Shirom 2001) will gravitate to social interactions where energy is gained and avoid those where energy is lost (Amah 2016; Owens et al. 2016).

\section{Leadership styles and levels of relational energy generation and transmitted}

The interaction ritual and social contagion theories jointly explain how energy is generated and transmitted from one individual to another in a social interaction. That the interaction with leaders energises or de-energises employees 
is well established; what is not properly stated is the nature of the energy generated and transmitted by different leadership styles. The level of relational energy generated and transmitted by a leader can be explained with the selfregulatory focus theory. Self-regulation is a conscious effort by individuals to control what they think and do so as to be who they want to be (Higgins 1998). It shapes peoples' motive, values and behaviours (Higgins 1997; 1998). Various leadership styles are driven by different motives and values, and each follows either the promotion or prevention foci in its self-regulation process (Higgins 1998). Self-regulation ensures that the motives and values that drive leadership behaviour are congruent with each other. Hence, the theory explains why there are differences in the levels of energy generated because different leadership styles have different motives and values which drive their behaviours. Leaders whose motives for leadership are people directed and who have values characterised as openness to change, selfdirecting, positive in challenging situations and willing to utilise problem-solving techniques, will subscribe to promotional focus. Those who see people as a means to an end and who have values characterised as conservative, always conforming, negative in challenging situations, always assuming the worse and do not drive for change will subscribe to prevention focus (Friedman \& Forster 2001; Higgins 1997; Kark \& van Dijk 2007). The former group will radiate positive energy and transmit the same to those who interact with them, while the latter group will radiate negative energy and de-energise those who interact with them (Friedman \& Forster 2001).

According to Brockner and Higgins (2001) and Kark and van Dijk (2007), transformational, transactional and autocratic leadership styles follow different self-regulatory paths because of their motives to lead and values placed on employees. Transformational leadership style is driven by the motive to lead and has great interest in the development of employees. Therefore, it will follow the promotion foci and energise those who interact with the leader. On the other hand, both transactional and autocratic leadership styles emphasise responsibility above employee development. They emphasise the need of people only if it will contribute to the task at hand. Thus, they are likely to follow the prevention foci and be de-energising to those who interact with them (Kark \& van Dijk 2007). The priority of each leadership style discussed so far is the goal of the organisation; however, servant leadership's main priority is the development of people.

The main motive of the servant leader is to serve people so that they can develop to their highest potential. The servant leader is authentic; he accepts people as they are, empowers and develops them and shows great concern for them (Dierendonck 2011). People are not a means to an end for him; they are actually the end of his efforts. During interaction with the servant leader, employees are encouraged to see obstacles as challenges that can be surmounted, and in doing so, to use problem-solving techniques. Hence, the servant leader will adopt promotion foci and energise employees (Stone et al. 2004). Transformational and servant leadership styles may both adopt the promotion self-regulatory foci; however, because the servant leader has a greater emphasis on people and places their need and development above all other things, the energy generated by the servant leader will be greater than that generated by the transformational leader.

Based on the above explanations, the following hypotheses are postulated:

$\mathrm{H} 1$ : There is a difference in the level of relational energy generated and transmitted when servant leaders and transformational leaders interact with their subordinates.

$\mathrm{H} 2$ : There is a difference in the level of relational energy generated and transmitted when servant leaders and transactional leaders interact with their subordinates.

H3: There is a difference in the level of relational energy generated and transmitted when servant leaders and autocratic leaders interact with their subordinates.

H4: There is a difference in the level of relational energy generated and transmitted when transformational leaders and transactional leaders interact with their subordinates.

H5: There is a difference in the level of relational energy generated and transmitted when transformational leaders and autocratic leaders interact with their subordinates.

H6: There is a difference in the level of relational energy generated and transmitted when transactional leaders and autocratic leaders interact with their subordinates.

\section{Methodology}

Scenario-based experimental design (Trochim \& Donnelly 2016) was used to determine whether various leadership styles generate and transmit different levels of relational energy. After I reviewed the review of literature on autocratic, transactional, transformational and servant leadership styles, each style was described with three or four sentences indicating key aspects of it. For example, the comments on servant and autocratic leadership styles are, respectively:

the leader's motive is to serve the subordinates first, so that they can grow and attain their utmost level of growth. The leader provides vision and credibility. The leader values followers first, and works towards their self-growth with the view that they willingly work for the organization. His relationship with his followers comes before any other within the organisation.

this leadership style is characterized by the leader's individual control over all decisions and little input from group members. The leader makes his choices based on his own ideas and judgement, and rarely accepts advice from followers. The leader has absolute and authoritarian control over the group. (Author)

Five leadership experts were approached to identify the styles after reading each description. They all properly 
TABLE 1: Analysis of variance analysis (dependent variable = average mean).

\begin{tabular}{lccccc}
\hline Source & Type III sum of squares & df & Mean square & $\boldsymbol{F}$ & Sig. \\
\hline Between groups & 194.284 & 3 & 64.761 & $* * 74.882$ & - \\
Within groups & 176.427 & 204 & 0.865 & - & -0.524 \\
Total & 370.711 & 207 & - & - & - \\
\hline
\end{tabular}

$\mathrm{df}$, Degree of freedom; F, statistics; Sig., Significance; **, $p<.01$.

TABLE 2: Tukey's honest significant difference multiple comparisons (dependent variable = average mean).

\begin{tabular}{|c|c|c|c|c|c|c|}
\hline \multirow[t]{2}{*}{ (I) Styles } & \multirow[t]{2}{*}{ (J) Styles } & \multirow[t]{2}{*}{ Mean difference $(\mathrm{I}-\mathrm{J})$} & \multirow[t]{2}{*}{ Std. Error } & \multirow[t]{2}{*}{ Sig. } & \multicolumn{2}{|c|}{ 95\% Confidence interval } \\
\hline & & & & & Lower bound & Upper bound \\
\hline \multirow[t]{3}{*}{ AUT } & $S L$ & $-2.5808 * *$ & 0.18238 & 0.01 & -3.0532 & -2.1083 \\
\hline & TF & $-2.0538 * *$ & 0.18238 & 0.01 & -2.5263 & -1.5814 \\
\hline & TRANS & $-1.3923 * *$ & 0.18238 & 0.01 & -1.8647 & -0.9199 \\
\hline \multirow[t]{3}{*}{ SL } & AUT & $2.5808^{*}$ & 0.18238 & 0.01 & 2.1083 & 3.0532 \\
\hline & TF & $0.5269 * *$ & 0.18238 & 0.05 & 0.0545 & 0.9994 \\
\hline & TRANS & $1.1885 * *$ & 0.18238 & 0.01 & 0.7160 & 1.6609 \\
\hline \multirow[t]{3}{*}{ TF } & AUT & $2.0538 * *$ & 0.18238 & 0.01 & 1.5814 & 2.5263 \\
\hline & SL & $-0.5269 *$ & 0.18238 & 0.05 & -0.9994 & -0.0545 \\
\hline & TRANS & $0.6615 * *$ & 0.18238 & 0.01 & 0.1891 & 1.1340 \\
\hline \multirow[t]{3}{*}{ TRANS } & AUT & $1.3923 * *$ & 0.18238 & 0.01 & 0.9199 & 1.8647 \\
\hline & SL & $-1.1885 * *$ & 0.18238 & 0.01 & -1.6609 & -0.7160 \\
\hline & $\mathrm{TF}$ & $-0.6615 * *$ & 0.18238 & 0.01 & -1.1340 & -0.1891 \\
\hline
\end{tabular}

Std. Error, Standard error; Sig., Significance; *, The mean difference is significant at the 0.05 level; **, The mean difference is significant at the 0.01 level; AUT, Autocratic leadership; SL, servant leadership; TF, transformational leadership; TRANS, transactional leadership.

Note: The error term is mean square (Error) $=0.865$.

identified the four leadership styles and stated that their differences were accurately captured in the descriptions. Prior to administering the questionnaires on the target sample, 40 participants attending a leadership executive programme were asked to check if there were differences in the descriptions of the leadership styles. They were alerted not to identify the leadership styles by name, but to spot out the differences if any. They all agreed that the descriptions were different. Thus, the experimental design was performed using these descriptions of the leadership styles.

\section{Measures}

Participants in two executive Master of Business Administration (MBA) classes were approached to participate in the study. Four different survey questionnaires were sent to the entire classes with 2 weeks in-between each survey. Each questionnaire contained the description of one leadership style (no name included) and five items of the relational energy taken from the work of Owens et al. (2016). The participants were asked to read the description and answer the question as to what they would feel if they interacted with the leadership style described. Sending the questionnaires in four separate periods reduced the bias that would have resulted if the participants received the descriptions in one single questionnaire. Fifty-two participants filled out the four different questionnaires (54\%). Of the participants, $60 \%$ were men, and each had had a tenure of more than 7 years.

\section{Results}

Prior to testing the difference in the values of the means, the study tested to confirm the assumptions needed for the application of analysis of variance (ANOVA). The study has four groups in the analysis, and the mean is continuous and independent. Plot showed that there were no outliers in the values of the means. However, test for normality showed that the distribution was not normally distributed $(t=0.119$, $p=0.01)$. ANOVA is very robust in situations of lack of normality (Schmider et al. 2010); hence, the analysis was carried out. Levene's test (Brown \& Forsythe 1974) of the equality of variance indicated equality of variance $(F=1.968$, $p=0.12)$.

The means for the relational energy generated through interaction with transformational, servant, transactional and autocratic styles are $3.74(S D=1.04), 4.24(S D=0.86), 3.05$ $(S D=0.97)$ and $1.66(S D=0.80)$, respectively. Analysis of the difference in the values of the means of relational energy generated by the leadership styles using ANOVA indicates that there were differences in the values of the means. Partial eta-squared value of 0.524 indicates that $27 \%$ of the variance in relational energy is accounted for by the variation in leadership styles. This is a large effect size going by the recommendation from Cohen (1988).

All the groups (leadership styles) have equal sizes; hence, Tukey's honest significant difference (HSD) method (Smith 1971) was used for pairwise comparison of means. Table 2 indicates that there were differences in each pair of mean. Thus, hypotheses 1-6 are all supported. Servant leadership style has the highest mean value of relational energy, while autocratic leadership style has the lowest.

\section{Discussion}

The study utilised scenario-based experimental methodology to explore the differential levels of relational energy generated when employees interact with leaders with different styles. 
ANOVA results indicated that there were differences in the values of the mean of relational energy generated when employees interacted with leaders enacting different styles. Tukey's HSD analysis for pairwise comparison of the means indicated that servant leadership has the highest mean value of relational energy. This is closely followed by transformational, transactional and autocratic leadership styles in that order. Past studies have demonstrated that relational energy is generated and transmitted when leaders interact with their subordinates (Amah 2016; Owens et al. 2016). Furthermore, leadership characteristics have been implied in studies involving relational energy (Aryee, Chay \& Chew 1996; Allen \& Eby 2003; Liebhart \& Faullant 2014). However, the author does not know of any study that has explicitly measured different leadership styles and explored whether their interactions with employees generate the same amount of relational energy. Thus, the results obtained went beyond past studies to establish that leadership styles are not equally effective in generating and transmitting relational energy. The fact that there are differences in the mean values of relational energy for different leadership styles confirms the accuracy of the manipulation of the leadership styles used in the study.

The results obtained make valuable contributions in the search for efficiency in organisations. Organisations must train their leaders to exhibit desired leadership behaviours such as servant leadership behaviours and avoid transactional and autocratic behaviours. This is because relational energy is an important resource in enhancing the productivity of highly engaged employees (Amah 2016). Amajor contribution of this study is the establishment of leadership styles that should be emphasised by organisations and those that should be discouraged based on their relationship with relational energy.

The findings in this study have various practical implications. Relational energy is an important organisational resource that is useful to employees in managing high work-family conflict and enhancing individual performance (Amah 2016). Thus, organisations must be interested in how best to generate and transmit this resource that greatly influences other important individual variables. The second practical implication of the current study is the realisation that all leadership styles are not equally efficient in generating and transmitting relational energy. Thus, organisations can tailor their training programmes to enhance servant leadership and transformational leadership behaviours and minimise transactional and autocratic leadership styles.

The participants were drawn from six industries: real estate, service, oil, financial, manufacturing and telecommunications. They were also in the senior to middle management level in their respective organisations. Generalisation outside the industries and job categories should be cautiously made. However, this should not be a serious issue because whenever people meet in any industry or job category, there is always a form of social interaction.

\section{Acknowledgements Competing interests}

The author declares that he has no financial or personal relationships which may have inappropriately influenced him in writing this article.

\section{References}

Allen, T.D. \& Eby, L.T., 2003, 'Relationship effectiveness for mentors: Factors associated with learning \& quality', Journal of Management 24, 469-486. https://doi. org/10.1016/S0149-2063(03)00021-7

Amah, O.E., 2016, 'Employee engagement and work-family conflict relationship: The role of personal and organizational resources', South African Journal of Labour Relations 40(2), 118-138.

Aryee, S.M., Chay Y.W. \& Chew, J., 1996, 'The motivation to mentor among managerial Employees', Group \& Organizational Management 21, 261-277. https://doi. org/10.1177/1059601196213002

Avolio, B.J., Walumbwa, F.O. \& Weber, T.J., 2009, 'Leadership: Current theories, research, and future directions', Annual Review of Psychology 60, 421-449. https://doi.org/10.1146/annurev.psych.60.110707.163621

Bernhard, F. \& O'Driscoll, M.P., 2011, 'Psychological ownership in small familyowned business: Leadership style and nonfamily-employees work attitudes \& behaviors', Group \& Organizational Management 36, 345-384. https://doi. org/10.1177/1059601111402684

Brockner, J. \& Higgins, E.T., 2001, 'Regulatory focus theory: Implications for the study of emotions at work', Organizational Behavior and Human Decision Process 86 , 35-66. https://doi.org/10.1006/obhd.2001.2972

Brown, M.B. \& Forsythe, A.B., 1974, 'Robust test for the equality of variance', Journal of American Statistical Association 69, 364-367. https://doi.org/10.1080/016214 59.1974.10482955

Bruch, H. \& Ghoshal, S., 2002, 'Beware the busy manager', Harvard Business Review $80,62-69$.

Casciaro, T. \& Lobo, M.S., 2008, 'When competence is irrelevant: The role of interpersonal affect in task-related ties', Administrative Science Quarterly 53 , 655-684. https://doi.org/10.2189/asqu.53.4.655

Chatbury, A., Beaty, D. \& Kriek, H.S., 2011, 'Servant leadership, trust and implication for the "Base-of-the-pay" segment in South Africa', South African Journal of Business Management 42(4), 57-61.

Cho, Y.S. \& Jung, J.Y., 2014, 'The verification of effective leadership style for TQM: A comparative study between USA-based firms and China-based firms', International Journal of Quality \& Reliability Management 31(7), 822-840. https://doi.org/10.1108/IJQRM-04-2013-0065

Cohen, J., 1988, Statistical power analysis for behavioral sciences, 2 nd edn., Lawrence Erlbaum, Hillsdale, NJ.

Collins, R., 1993, 'Emotional energy as the common denominator of rational action', Rationality and Society 5, 203-230. https://doi.org/10.1177/ 1043463193005002005

Collins, R., 2004, Interaction ritual chains, Princeton University Press, Princeton, NJ.

Cross, R., Baker, W. \& Parker, A., 2003, 'What creates energy in organizations?' MITSloan Management Review 44(4), 51-56.

Dierendonck, D., 2011, 'Servant leadership: A review and synthesis', Journal of Management 37(4), 1228-1261. https://doi.org/10.1177/0149206310380462

Dierendonck, D., Stam, D., Boersma, P., de Windt, N. \& Alkema, J., 2014, 'Same difference? Exploring the differential mechanisms linking servant leadership and transformational leadership to follower outcome', The Leadership Quarterly 25 544-562. https://doi.org/10.1016/j.leaqua.2013.11.014

Friedman, R.S. \& Forster, J., 2001, 'The effects of promotion and prevention cues on Creativity', Journal of Personality and Social Psychology 81, 1001-1013. https:// doi.org/10.1037/0022-3514.81.6.1001

Hartfield, E., Cacioppo, J.T. \& Rapson, R.L., 1994, Emotional contagion, Cambridge University Press, New York.

Higgins, E.T., 1997, 'Beyond pleasure and pains', American Psychologist 52, 12801300. https://doi.org/10.1037/0003-066X.52.12.1280

Higgins, E.T., 1998, 'Promotion and prevention: Regulatory focus as a motivational principle', in P.Z. Mark (ed.), Advances in experimental social psychology, vol. 30, pp. 1-40, Academic Press, New York.

Hobfoll, S.E., 1989, 'Conservation of resources: A new attempt at conceptualizing stress', American Psychologist 44, 513-524. https://doi.org/10.1037/0003066X.44.3.513

Hobfoll, S.E. \& Shirom, A., 2001, 'Conservation of resources theory: Applications to stress and management in the workplace', in R.T. Golembiewski (ed.), Handbook of organizational behavior, pp. 57-80, Marcel Dekker, New York.

Holten, A. \& Brenner, S.T., 2015, 'Leadership style and the process of organizational Change', Leadership \& Organization Development Journal 36, 2-16. https://doi. org/10.1108/LODJ-11-2012-0155

Kark, R. \& van Dijk, D., 2007, 'Motivation to lead, motivation to follow: The role of selfregulatory focus in leadership process', Academy of Management Review 32(2), 500-528. https://doi.org/10.5465/amr.2007.24351846 
Liebhart, U. \& Faullant, R., 2014, 'Relational energy as a booster for high quality relationship in mentoring', paper presented at the European Academy of relationship in mentoring, paper prese
management, Valencia, June 4-7, 2014.

Lyons, J.B. \& Schneider, T.R., 2009, 'The effects of leadership styles on stress outcomes', The Leadership Quarterly 20, 737-748. https://doi.org/10.1016/j. leaqua.2009.06.010

Moorosi, P. \& Bantwini, B., 2016, 'School district leadership styles and schoo improvement: Evidence from selected school principals in the eastern Cape Province', South African Journal of Business Management 36(4), 1-9.

Owens, B.P., Baker, W.E., Sumpter, D.M. \& Cameron, K.S., 2016, 'Relational energy a work: Implications for job engagement and job performance', Journal of Applied Psychology 10(1), 35-49. https://doi.org/10.1037/apl0000032

Quinn, R.W., Spreitzer, G.M. \& Lam, C.F., 2012, 'Building a sustainable model of human energy in organizations: Exploring the critical role of resources', The Academy of Management Annals 6, 337-396. https://doi.org/10.5465/19416520.2012.676762

Saeed, T., Almas, S., Anis-ul-Haq, M. \& Niazi, G.S.K., 2014, 'Leadership styles: Relationship with conflict management styles', International Journal of Conflict Management 25(3), 214-225. https://doi.org/10.1108/IJCMA-12-2012-0091
Schaufeli, W.B., Salanova, M., Gonzalez-Roma, V. \& Bakker, A.B, 2002, 'The measurement of engagement and burnout: A two sample confirmatory factor analytic approach', Journal of Happiness 3(1), 71-92. https://doi. org/10.1023/A:1015630930326

Schippers, M.C. \& Hogenes, R., 2011, 'Energy management of people in organizations: A review and research agenda', Journal of Business Psychology 26, 193-203. https://doi.org/10.1007/s10869-011-9217-6

Schmider, E., Ziegler, M., Dany, E., Beyer, L. \& Buhner, M., 2010, 'Is it really robust? Reinvestigating the robustness of ANOVA against violations of the normal distribution', European Journal of Research Methods for the Behavioral \& Sciences 6(4), 147-151. https://doi.org/10.1027/1614-2241/a000016

Smith, R.A., 1971, 'The effect of unequal group size on Tukey's HSD', Psychometrika 36(1), 31-34. https://doi.org/10.1007/BF02291420

Stone, G., Russell, R.F. \& Patterson, K., 2004, 'Transformational versus servant leadership: A difference in leader focus', Leadership \& Organizational Developmen Journal 25, 349-361. https://doi.org/10.1108/01437730410538671

Trochim, W. \& Donnelly, J.P., 2016, Research methods: The essential knowledge base, 2nd edn., Wadsworth Publishing, New York. 